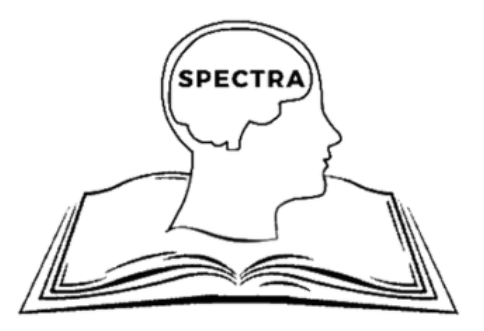

Spectra Undergraduate Research Journal

Volume 2, Issue 1

Office of Undergraduate Research

University of Nevada, Las Vegas

digitalscholarship.unlv.edu/spectra/

\begin{tabular}{|c|}
\hline Category \\
\hline Arts, Humanities, and Social Sciences $>$ Social Sciences $>$ Psychology \\
\hline Received \\
\hline October 18,2021 \\
\hline Accepted \\
\hline February 18,2022 \\
\hline Published \\
\hline February 28,2022 \\
\hline Article Title \\
\hline A Systematic Literature Review on the Resilience Reported by BIPOC in the Face of Discrimination \\
\hline Authors \\
\hline Lianelys Cabrera Martinez (LCM) ${ }^{1 *}$, Aldo Barrita (AB) ${ }^{1}$, and Gloria Wong-Padoongpatt, Ph.D. ${ }^{1}$ \\
\hline Author Affiliations \\
\hline${ }^{1}$ Department of Psychology, University of Nevada, Las Vegas, Las Vegas, NV, USA. \\
\hline Corresponding Author \\
\hline $\begin{array}{l}\text { *Lianelys Cabrera Martinez, cabre13@unlv.nevada.edu } \\
\text { (iD) https://orcid.org/0000-0002-4020-9613 }\end{array}$ \\
\hline Author Contributions \\
\hline $\begin{array}{l}\text { LCM: Collected articles, analyzed and selected literature using the PRIMA method, drafted the manuscript and made } \\
\text { significant edits to the manuscript. } \\
\text { AB: Substantially contributed to the research design, data collection, analysis, and interpretation, revised the } \\
\text { manuscript critically, and approved the version to be published. } \\
\text { GWP: Substantially contributed to the research design, data collection, analysis, and interpretation, revised the } \\
\text { manuscript critically, and approved the version to be published. }\end{array}$ \\
\hline Copyright \\
\hline $\begin{array}{l}\text { (C) } \rightarrow \text { Articles in Spectra are freely available under a Creative Commons Attribution License (CC BY } \\
\text { 4.0) which allows others to re-use the work without permission as long as the work is properly } \\
\text { cited. }\end{array}$ \\
\hline ISSN \\
\hline $2766-7227$ \\
\hline Data Availability Statement \\
\hline The authors of this article confirm that all data underlying the findings are fully available without restrictions. \\
\hline The authors declare that they have no conflict of interest. \\
\hline Ethical Considerations \\
\hline $\begin{array}{l}\text { Given that this project did not involve human or animal subjects, no IRB or IACUC approval was needed. No data } \\
\text { are presented in this paper derived from the participants. }\end{array}$ \\
\hline Funding \\
\hline This project was funded by the McNair Summer Research Institute at UNLV. \\
\hline Recommended Citation \\
\hline $\begin{array}{l}\text { Cabrera Martinez, L., Barrita, A., \& Wong-Padoongpatt, G. (2022). A systematic literature review on the resilience } \\
\text { reported by BIPOC in the face of discrimination. Spectra Undergraduate Research Journal, 2(1), 1-13. } \\
\text { https://doi.org/10.9741/2766-7227.1012 }\end{array}$ \\
\hline
\end{tabular}




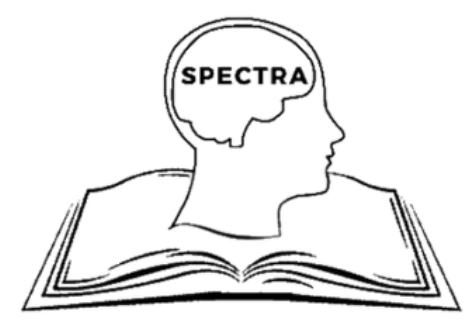

Spectra Undergraduate Research Journal

Volume 2, Issue 1

Office of Undergraduate Research

University of Nevada, Las Vegas

digitalscholarship.unlv.edu/spectra/

\title{
A Systematic Literature Review on the Resilience Reported by BIPOC in the Face of Discrimination
}

\author{
Lianelys Cabrera Martinez ${ }^{1}$, Aldo Barrita ${ }^{1}$, and Gloria Wong-Padoongpatt, Ph.D. ${ }^{1}$
}

\section{Author Affiliations:}

${ }^{1}$ Department of Psychology, University of Nevada, Las Vegas, Las Vegas, NV, USA.

\begin{abstract}
The present study is a systematic literature review on the psychology of resilience, or the ability to bounce back after a difficult situation (Smith, 2008). Although resilience is a timely and relevant variable in social psychology, little is known about its connection to the racism-related experiences of Black, Indigenous, and People of Color (BIPOC). This review explores how resilience manifests in the BIPOC community and its influence on the identity of minority groups. Previous research has shown that BIPOC reports higher resilience (Carter, 2012); however, there is still uncertainty around its connection to discrimination. Through the analysis of nine final research articles, we examined four main questions: (a) What is the prominent definition of resilience?, (b) How is resilience experienced or manifested among BIPOC?, (c) How is resilience operationalized when experiencing oppression?, and (d) What are the limitations in the literature of resilience? Results shed light on the need to further investigate resilience as a protective factor against discrimination in the BIPOC community.
\end{abstract}

Keywords: Resilience, discrimination, racial and ethnic minorities, BIPOC

The term resilience has been widely debated in various fields, including psychology, sociology, engineering, and even ecology (Boureau, 2018). Due to the COVID-19 global pandemic, there has been a growing interest among experts around resiliency (PeConga et al., 2020). How likely are people to bounce back from difficult situations? Is this response attributed to inherited traits? Is resilience a protective factor? These are questions that stem from the enigmatic topic of resilience, which encourages experts to expand on resilience's literature and definitions.

Research on resilience has grown over the recent decades (Luthar et al., 2000), becoming a relevant concept in fields like biology (Curtis \& Cicchetti, 2003), widely discussed in psychological practices ( $\underline{\mathrm{Hu}}$ et al., 2015), and described as a protective factor (Ungar, 2013). Knowledge on specific aspects of resilience, however, is still limited.
For example, there is a substantial gap to be filled in the literature when we explore the resilience experienced by Black, Indigenous, and other People of Color (BIPOC) in the face of racial discrimination. Experts demonstrate that resilience is a measurable response often displayed by BIPOC, which highlights resilience as a coping strategy for discrimination (Brown \& Tylka, 2011; Carranza, 2007).

Resilience is generally defined in social psychology as the capacity to recover from stress or "to bounce or spring back" (from re- "back" + salire- "to jump, leap"; (Agnes, 2005). The word resilience alludes to factors needed to conquer obstacles or difficulties, such as strength, hardiness, and resistance. Interestingly, several researchers have tried to measure the core aspects of resilience, creating variations and disagreements in both definition and measurement (Smith, 2008). Resilience, in all its complexities, is an 
essential social phenomenon to consider because it can serve as a coping strategy for everyday acts of racism and racial attacks. However, there is limited work on resilience amongst BIPOC, particularly around experiences of discrimination. The field needs to examine the specific levels of coping mechanisms that racially minoritized groups use to interact with their ethnic identity, environment, and social groups to confront discriminatory acts.

Resilience can also be interpreted as a protective factor against adverse situations. Researchers such as Bakić (2019) have described resilience as the action of sustaining and recovering psychological well-being in the face of adversity. Similarly, the literature has suggested that BIPOC are significantly more affected by racial attacks (Sue et al., 2019). These discriminatory acts often lead to complex psychological responses both immediate and cumulative such as resilience (Carranza, 2007). Nonetheless, the literature makes special emphasis on the role that resilience plays when people experience discrimination. In some cases, specific types of resistance such as cultural resilience help repair the detrimental impact of racism in the form experienced by BIPOC (Spence et al., 2016). Thus, demonstrating that resilience can operate as a protective factor against discriminatory acts. This ultimately leads to the question: if BIPOC were "more resilient," could they then, protect themselves better against discrimination?

A common framing of resilience within the context of discrimination is to emphasize that resilience is a needed trait to overcome discrimination (Barrita \& Wong-Padoongpatt, 2021, in press). The highlighting of resilience as a natural trait can be detrimental to the individual, especially for BIPOC who are often categorized as naturally strong (Guyll et al., 2010). We deviate the focus from the systems of oppression when attributing this inherited resilience and inappropriately assign the label of resilience to those who are marginalized by the system. Protective resilience suggests BIPOC who have such resilience can better recover or shield from racial oppression (Austin et al., 2021). A review of the literature is needed to assess if such current definitions of resilience are still supported. It is also equally important to summarize how the BIPOC reports resisting discriminatory acts to understand the role and origin of their resilience. Thus, I conducted a systematic literature review on resilience when navigating racial discrimination as the principal focus. Additionally, I reviewed the measurements used for resilience in these studies as well as their limitations.

\section{Resilience: Trait vs. Protective Response}

Resilience is commonly debated as a natural trait versus a response to external factors. Scholars have discussed that: (a) resilience is a component of the environment and its ability to provide the growth and not an individual factor; (b) resilience varies depending on the population being examined and is susceptible to individual, external, and cultural phenomena; and (c) risk exposure plays a significant role on the effect that external components have on resilience, demonstrating the influence of contextual and cultural variation (Ungar, 2013). Studies using African American samples have systematically argued that reports of receiving general racial socialization messages, as well as specific messages to appreciate cultural legacy, were associated with higher levels of African Americans' resilience when they reported high levels of racial discrimination (Brown \& Tylka, 2011). The literature exposes the concept of resilience as a consequence of environmental forces shaping the response of the individual. Therefore, challenging other frames of resilience as an inherent trait that specific populations possess.

Nonetheless, some scholars cite resilience as a naturally-inherited psychological trait ( $\mathrm{Hu}$ et al., 2015; Liu et al., 2014). Although limited, some researchers have examined resilience among BIPOC. For instance, Marsiglia et al. (2013) examined the increase of the Mexican American population and found that acculturation, an internal mechanism, is frequently connected with resilience when experiencing immigration-related stress (Marsiglia et al., 2013). People with multiple marginalized identities are often described as "more resilient" based on their ability to overcome multiple systems of oppression (Aguilera \& Barrita, 2021). A review of the literature is necessary given the discrepancy in the origin and mechanism for resilience. Especially when scholars have begun to challenge these views and argued that BIPOC's resilience is the byproduct of systemic and generational oppression and as such it should not be romanticized as a "wanted trait" and instead should call for the 
abolition of such oppressive systems (Barrita \& WongPadoongpatt, in press).

\section{Resilience Scales}

As stated before, there are gaps in the literature about the factors that influence resilience, including a need to further examine the scales utilized to measure this variable. Still, the literature looking at the display of resilience have found significant results for all regression coefficients of resilience scales (Karaman et al., 2019). There are approximately eight different scales that measure resilience in the current literature which include The Connor Davidson Scale (CD-RISC) and The Brief Resilience Scale (BRS) (ConnorDavidson, 2003; Smith, 2008). While there has been a clear development of resilience scales, it is not clear if such scales can be used for resilience when experiencing discrimination. In fact, most studies used alternative measures to assess resilience, with CDRISC being one of the very few quantitative measures being used in research studies. The Connor-Davidson Resilience Scale (CD-RISC) is a 25-item scale with adequate psychometric properties in terms of resilience, more specifically when measuring youth's resilience (Campbell-Sills \& Stein, 2007). There are different versions of the scale, such as the CD-RISC10 (Heritage et al., 2021), which is the shorter variant, and one that reflected modest psychometric properties and maintained a parsimonious way of evaluating resilience. The Cronbach's alpha of 0.88 CI [0.86, 0.90] (Karairmak, 2009) for the 25-item version is noteworthy since it represents a satisfactory level of validity and reliability. Additionally, CD-RISC has been tested in Spanish-speaking samples showing great psychometric properties for this population (Guarnizo Guzmán et al., 2019). Experiencing resilience when facing discrimination remains to be an important focus of the research because of the continuous and current racial tension BIPOC experience in the US (Silver, 2021). This review aims to summarize how far we have come in this topic and what gaps are we missing.

\section{Research}

Based on the framework discussed, this review aimed to answer a) What is the prominent definition of resilience?, (b) How is resilience experienced or manifested among BIPOC?, (c) How is resilience operationalized when experiencing discrimination?, (d) What are the limitations in the literature of resilience? This study used a PRISMA method of systematic literature analysis. Our study primarily focused on resilience, emphasizing its relationship with discrimination among BIPOC, and provides a detailed summary of common findings in our review.

\section{Methods}

Protocol and Registration: The initial objective was to search for articles in academic databases, which included EBSCO, APA PsychINFO, and Sociological Abstracts. The search protocol was conducted in a period of two weeks, followed by a critical inclusion and exclusion process that lasted approximately an additional two weeks. The overall process lasted from June 2021 until July 2021.

Search Strategy and Inclusion Criteria: In the first phase of the search, we focused on the titles of the articles. Using the advanced search feature in all three databases (EBSCO, APA PsychINFO, and Sociological Abstracts), we looked for titles that included key terms "resilience AND discrimination". Moreover, we only included peer-reviewed, full-text available, and published in the last decade, more specifically from 2011 to 2021 (See Appendix A).

To explore the relevant articles and research questions, the PRISMA method was used for this review. The PRISMA method is frequently used by scholars when conducting systematic literature reviews. This evidence-based procedure primarily centers on summarizing findings and evaluating the effectiveness of the measures used in the pertinent studies (PRISMA, 2021). Additionally, it is used for systematic reviews to evaluate the relevance of the topic of interest. The PRISMA method consists of identifying relevant articles by searching databases, removing duplicates, assessing the selected articles for eligibility, removing articles that do not meet inclusion criteria, identifying themes among the articles, and finally analyzing those themes.

Study Selection: The initial advanced search of the words resilience AND discrimination in the title of peer-reviewed articles published in the last decade (from 2010 to present-day) from the database EBSCO, were narrowed from 2,745 results to 101, after eliminating duplicates, and later to 9 chosen titles. The initial advanced search of the words resilience AND discrimination in the title of peer-reviewed articles published in the last decade from the database APA 
PsychINFO, were narrowed from 79 results to 1 chosen article. The initial advanced search of the words resilience AND discrimination in the title of peerreviewed articles published in the last decade from the sociological abstracts database, were narrowed from 20 results to two chosen relevant titles.

A more specific search was conducted to prioritize the importance of resilience, and this time, only looked for articles that included resilience in the title. We were able to narrow down the EBSCO search from 145,297 results to 223 after eliminating duplicates. Lastly, we chose 5 relevant tiles using the same criteria mentioned before, but this time specifying the subject of psychology. The same method was applied to APA PsychINFO, and the search results were narrowed from 18,485 to 6,147 and then 9 titles were chosen. Finally, the Sociological Abstracts database, specifying the subject of resilience, showed 11,361 results that were reduced to 2,901, from which 5 articles were selected (see Figure 1 below).

Included Studies: After this meticulous review of the results from the initial search, a complete number of 31 relevant titles were selected for revision and we proceeded to move to the second phase of the protocol. In the second phase, the focus was shifted to the abstract content of the articles chosen in the first round, this time emphasizing the relevance to the main topic. Overall, the criteria were to look for abstracts that focused on the concept of resilience and showed its relation to discrimination, also having in mind the BIPOC experience. In this round of inclusion and exclusion criteria, we selected 13 relevant articles, from which we removed 4 because they were related to the analysis of resilience scales, leaving us with 9 articles in total for this systematic literature review.

\section{Synthesis of Results:}

\section{Figure 1.}

Summarized search

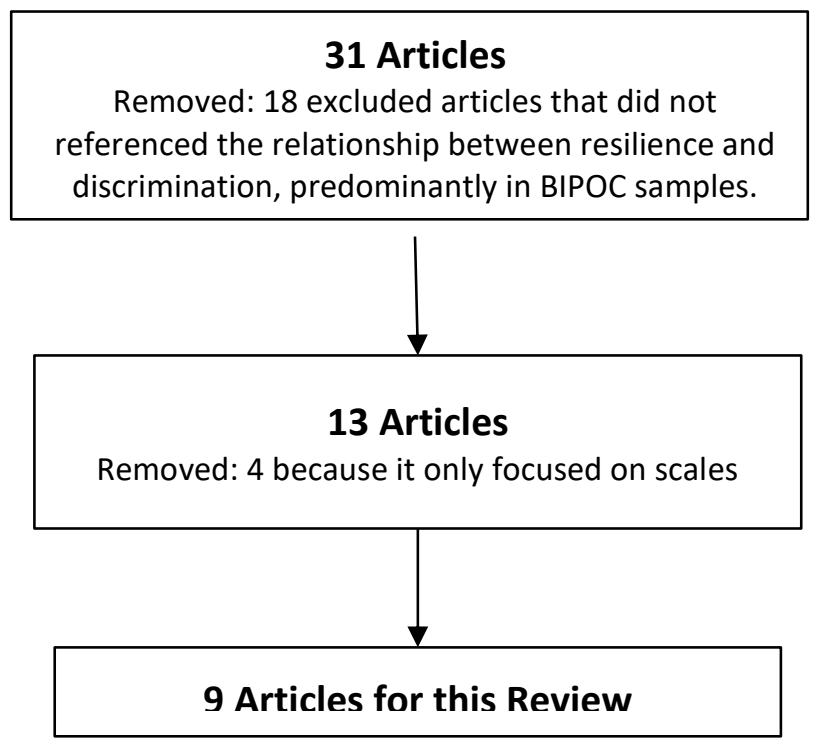

\section{Results}

Nine research articles were selected for the final phase of this systematic review after following our elimination criteria. This review strictly selected research that focused on resilience and racial discrimination reported by BIPOC. There were multiple studies that centered on resilience and provided a comprehensive investigation on the term but did not center on BIPOC experiences. See the flow diagram below (see Figure 2 below) to analyze the synthesized version of the study selection.

Figure 2.

Synthesis of study selection

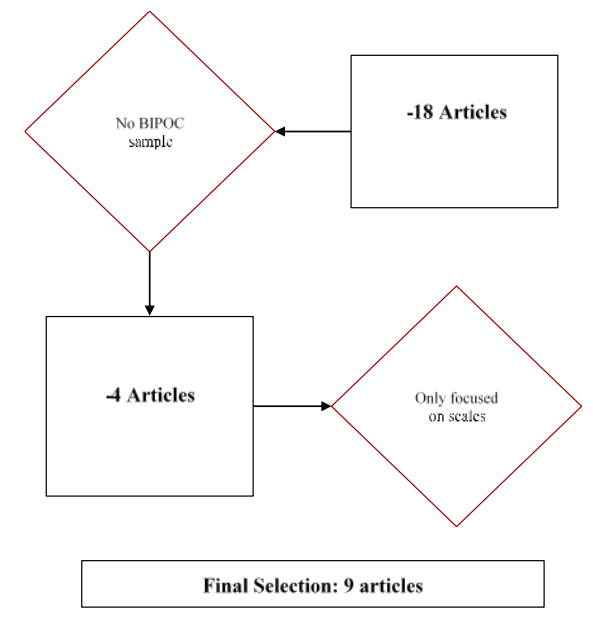


Summary of Included Studies

1.Racial Discrimination, Ethnic-Racial Socialization, and Crime: A Micro-sociological Model of Risk and Resilience (Burt et al., 2012).

This study focused on the relationship between racial-driven stress and resilience. Their sample $(\mathrm{N}=$ 897) included Black African American families. The authors considered ethno racial socialization an adaptive factor of the African American community. It was found that cultural socialization recompenses for the detrimental effects of racial discrimination influencing their resilience. This study discusses how cultural socialization affected the levels of resilience and crime in the face of racial discrimination.

2. Mixed Resilience: A Study of Multiethnic Mexican American Stress and Coping in Arizona (Jackson et al., 2013).

This is an in-depth qualitative study discussing the stressors Mexican American individuals with a multiethnic background experience in their everyday lives, while also investigating the resilience and coping strategies used to confront such stressful situations. After the coding of 24 narratives, the results suggested that subjects identified support, interpersonal and internal protective processes as the main approaches to deal with racial discrimination.

3. Understanding the Role of Collective Racial Esteem and Resilience in the Development of Asian American Leadership Self-Efficacy (Kodama et al., 2020).

This study uses a structural approach modeling to discuss the enhancement of leadership self-efficacy and its relationship to racial identity in connection to resilience. More specifically, the study explores the novel association between collection racial esteem and resilience. Findings corroborate the importance of racial identity on leadership skills improvements in Asian American individuals when building resilience.

4. The Relationships Between Loneliness, Social Support, and Resilience Among Latinx Immigrants in the United States (Lee et al., 2020).

This study analyses a Latinx sample's experiences as immigrants and their consequent generational effects. The study found that the Latinx immigrant population uses social support as a way to resist and cope with detrimental experiences of the immigration journey in life.
5. The Response of Youth to Racial Discrimination: Implications for Resilience Theory (Kubiliene et al., 2015).

This qualitative study used a BIPOC youth sample to explore racial discrimination and resilience. They emphasized that adolescents are not equally affected by racial discrimination or racially charged situations, and consequently, the coping mechanism utilized will depend on the individual and their environment. Results identified 3 recurrent coping methods as resilient: expressive emotional healing, spiritual forgiveness, and communicative-relational methods.

6. Resilience to Discrimination Stress Across Ethnic Identity Stages of Development (Romero et al., 2014).

This cross-sectional self-report study with 125 ethnic minority adolescents looked at the relationship between discrimination and resilience. They found that higher levels of race-based stress were associated with more protective factors such as resilience which enhance self-esteem and lower the likelihood of depression.

7. Latino Adolescents' Perceived Discrimination in Online and Offline Settings: An Examination of Cultural Risk and Protective Factors (Umaña-Taylor et al., 2015).

This study examined the associations between the ideas of Latinx youth around ethnic discrimination in various settings, such as discrimination in school environments vs. online situations as well as factors such as positive ethnic identity attitudes that could influence how these situations were experienced. Results lead to three different ethnic identity factors as resilience: exploration, resolution, and affirmation.

8. Racial Discrimination and Resilience in African American Young Adults: Examining Racial Socialization as a Moderator (Brown \& Tylka, 2011).

This study used Black and African American individuals to investigate the role of racial socialization in building resilience. Findings suggested that resilience and racial discrimination present a negative relationship, especially for those who experienced lower levels of racial socialization in their lifetime.

9. Racial Discrimination, Racial Socialization, and Crime: Understanding Mechanisms of Resilience (Burt et al., 2017).

This study used a Black and African American sample to explore the relationship between racial 
socialization and resilience. The results suggest that a familiar method of racial socialization is associated with resilience in terms of the criminogenic results of racial discrimination mainly by enhancing racial identity attitudes and spirituality.

What is the prominent definition of resilience among BIPOC? This quintessential question was prioritized in the hopes of finding an objective and allencompassing definition of the term "resilience." The standard definition of the term is often connected with the ability to bounce back after difficulty (Smith et al., 2008). Although seemingly simple to conceptualize, we found that the nine articles provided a different perspective on the term. In terms of the BIPOC community, that standard definition of resilience becomes more complex. Nonetheless, there were some punctual similarities among the approach the authors took. For instance, three of the studies refrained from providing an explicit definition of resilience and rather discussed it in combination with racial socialization (Burt et al., 2012; Brown \& Tylka, 2011; Burt et al., 2017). Despite this trend, a significant portion of the authors, whether they provided a strong definition, described resilience as a protective factor (Burt et al., 2017; Kodama et al., 2020; Kubiliene et al., 2015). Among the different definitions, Jackson et al. (2013) provided a direct conceptualization of the term, stating that it can be referred to as a dynamic and extensive process in which the person interacts with their environment to yield favorable results. Although this definition is not as extensive as those provided by previous studies, it provides an understanding of the nature of the term while deviating from the traditional view of resilience as an inherited trait.

On the other hand, among the differences between the studies when referring to resilience. Around four of the studies used the concept as a theoretical framework to guide their research and in that way, combined it with other theoretical concepts, such as racial-ethnic attitudes (Burt et al., 2017). Moreover, some authors marked the distinction in their conceptualization of resilience tailoring it to the topic of the research. For instance, Kodama (2020) in the study of resilience in the construction of leadership efficacy in Asian Americans defined resilience in relation to leadership processes and collective racial esteem. Similarly, another study that focused on the resilience shown in Latinx adolescents online and offline, defined resilience based on the resources Latinx teens use to shield themselves from the detrimental effects of discrimination (Umaña-Taylor et al., 2015).

After analyzing these findings, it can be inferred that the literature lacks an objective and allencompassing definition for the term resilience. Interestingly, most authors do not provide an explicit definition for the concept and instead focus on the discussion of resilience in combination with relevant, but different factors. Not only that, but two of the nine authors shifted the definition in a way that fitted the theme of the article (Jackson et al., 2013; Kodama et al., 2020). Despite these disadvantages in our search, one of the strongest patterns among all articles is the idea of resilience as a protective factor in the face of discrimination (Romero et al., 2014). More importantly, some studies implied the importance of external factors that lead to effective coping strategies such as a resilient mentality and attitude, therefore the most appropriate definition found in this systematic review reveals that resilience is a complex process in which the individual and the environment interconnect to create a protective and positive result (Jackson et al., 2013). Still, future researchers should aim to write a definition of resilience that is more extensive and comprehensive of the nuance of the term.

How is resilience experienced or manifested among BIPOC? As evident in the literature review, resilience is experienced in varied ways among BIPOC, and hence, research in this area is imperative. Therefore, understanding the different levels of resilience contributes to the overall understanding of the BIPOC experience. For instance, resilience is connected to the acceptance and positivity of the ethnic identity of the participants in some of the selected studies (Jackson et al., 2013). This means that the more comfortable and familiar individuals were with their racial identity, the more resilience they reported. Often this resilient behavior was connected to cultural and racial socialization, to cope with the effects discrimination has on BIPOC in three of the studies (Burt et al., 2012; Brown \& Tylka, 2011; Burt et al., 2017). Burt et al. (2012) interprets this relationship between resilience and ethnic identity familiarization as a protective factor utilized by BIPOC to enhance and create a prideful mindset in the minority community to provide tools to cope with racism. 
Moreover, resilience looks differently depending on the type of study. In this sense, resilience is represented in positive racial identity, interpersonal strengths, external supports, persistence in challenging work environments, and adaptation to different environments (Lee et al., 2020; Kubiliene et al., 2015; Romero et al., 2014; Umaña-Taylor et al., 2015). We found that the strongest themes among the nine research articles are positive racial identity and external support. The literature shows an interesting connection between resilience and the importance of having a positive and strong attitude towards one's ethnic identity (Brown \& Tylka, 2011). Not only that, but having a social support system can help minority groups cope with discriminatory stressors in a healthy manner (Lee et al., 2020). In this sense, resilience can be interpreted as a coping mechanism against discrimination. In that sense, seeking support from others is a method of coping with the detrimental effects that discrimination has on BIPOC. Similarly, adapting to different situations can be considered a direct reaction to discriminatory environments.

How is resilience operationalized when experiencing discrimination? A number of the authors did not operationalized resilience with a scale or traditional form of measurement. Instead, the studies put resilience as a framework to guide their studies (Burt et al., 2012; Umaña-Taylor et al., 2015; Brown \& Tylka, 2011; Burt et al., 2017). When resilience is framed as a theory, scholars take time to deeply analyze and comprehend how this concept influences the relationship between other phenomena, such as discrimination and self-esteem, or discrimination and leadership efficacy (Kodama et al., 2020; Romero et al., 2014). In an earlier study conducted by Burt et al. (2012) discussed resilience as a direct byproduct ethnic-racial socialization. Another minor pattern is the use of the different versions of the Connor-Davidson Scale (CD-RISC) in three of the nine studies (Kodama et al., 2020; Lee et al., 2020; Brown \& Tylka, 2011). Although different scholars used different versions of the scale, in essence, the Connor-Davidson scale required participants to respond to items regarding their likelihood of managing difficult situations such as I am able to adapt when changes occur. The only distinction among the articles is that one of them did not use a specific method of resilience, and instead integrated the concept into the interview process of focused groups (Kubiliene et al., 2015). Resilience as a theoretical framework is vital because it provides meaningful and helpful information about the concept and its relationship to other significant variables. However, given that only three of the studies used a reliable and valid method of operationalization, future research on resilience should seek to prioritize objective measurement procedures that are replicable in future studies.

What are the limitations in the literature of resilience? Each study presented specific limitations depending on their methodological approach and the nature of the study. Despite these differences, there are three major limitations mentioned in at least five of the nine studies. First, many studies presented a limited sample, both in terms of size and ethnic diversity. Consequently, the second limitation of many studies was the generalizability of the results. Given that the sample in many of the studies was limited, readers and other researchers are warned that the results might not be generalizable to a bigger population. In the study of the different mechanisms of resilience, Burt et al. (2017) specified that the sample only included African American families from Iowa and Georgia, therefore as readers, we have to be cautious when generalizing their findings to the whole BIPOC and African American community. Similarly, in a study regarding social support and resilience in Latinx immigrants, Lee, and other scholars (2020), mentioned that their results are exclusively representative of the Latinx immigrant community, but findings were not to be generalized to populations outside of Latin America.

Finally, a less popular but still relevant theme among these studies was the social desirability reflected in the responses provided by participants. In general, many researchers used self-report methods to measure resilience and other experiences around discrimination, which has a high probability of bias and likelihood of socially desirable answers. According to different studies, many participants reported higher levels of microaggressions than expected, which can be a result of participants responding in a way that is favorable rather than completely honest (Lee et al., 2020). Other limitations mentioned include the use of scales with low validity and reliability, low internal consistency of scales, lack of causal relationship, and the use of convenient samples. 
One of the studies indicated that it involved a convenience sample of African Americans affiliated with one Midwestern university, which may differ from African Americans in the larger community. There may be important regional differences that were not reflected in this sample. Consequently, readers are cautioned about making generalizations to the African American community as a whole (Brown \& Tylka, 2011). This is a recurrent limitation in several of the studies regardless of the sample ethnic or racial background. Another risk of bias is the lack of a comparison group because all the articles focus on a specific population. When studying a particular minority group, it is also important to address a comparison population to make a more valuable and less biased argument.

\section{Discussion}

Based on the literature review, there is some inconsistency on how resilience was defined and conceptualized. These questions are equally relevant to the literature and demonstrate the novelty of the study. This study aimed to review the literature of resilience, with the purpose to have a better understanding of the term and find a fit comprehensive definition. Moreover, we sought to evaluate how resilience is reflected emotionally and behaviorally in the BIPOC community, and the different measures utilized to evaluate this concept. These findings, while limited in some respects, begin to shed light on the need to better define and study this topic in the academic field of psychology, which as mentioned before, has not been explored in great detail. In this way, our study provides new approaches to the literature, and the possibility to expand more on our initial limited analysis. Additionally, there are some factors about this study that impeded better results, which include the strength of meta-analysis, generability, lack of comparison with other racial minority groups.

Furthermore, after analyzing the ways in which resilience is manifested in the BIPOC community, results show strong themes among the nine research articles including positive racial identity and external support, meaning that developing a positive attitude towards your ethnic identity and having a support system can assist in finding healthy coping strategies, such as resilience (Brown \& Tylka, 2011; Lee et al., 2020). However, future researchers need to aim to create a definition of resilience that is more extensive and comprehensive of the nuance of the term. Most studies described resilience as a coping mechanism against discrimination and the stress such experiences generate among BIPOC. Additionally, the review found that seeking support from others is often serves as another coping method for discrimination. And, adapting to different situations can be considered a direct reaction and form of resilience in discriminatory environments. However, the strongest reflector of resilience across these studies was when one experiences a positive attitude towards their own ethnic-racial identity. Finally, although there was an initial expectation to find psychometric measurements of resilience in the chosen literature, the opposite occurred. Many of the studies instead used resilience as a guiding principle to understand the way people of color deal with discrimination but chose not to use quantitative measures to assess it.

\section{Future Directions}

Research on oppression has indicated that marginalized groups utilize strategies to cope and defend themselves from such oppression (Sanchez et al., 2018). Research on resilience and discrimination over marginalized groups has shown that there is not a clear understanding of how one influences the other, although a relationship is suggested (Wittrup et al., 2019). Given what we know about racial discrimination and resilience, one should wonder to what extent both are associated? Despite the significant interest in everyday discrimination research that has increased in the last decade (Wong et al., 2014), there is still an unexplored territory when it comes to coping mechanisms such as resilience. Furthermore, the development of measures for resilience is still limited compared to other psychological phenomena.

Future research could focus on the analysis of the peculiarities among the experience of resilience between different racial minority groups. Our study indicates an initial approach to further shed light on the differences and similarities in the BIPOC community, which although shares a common stressor, deal with this discrimination in different forms. There is a desperate need for research that studies the levels of resilience among and between the BIPOC community. Not only that but there is a lack of in-depth cross- 
cultural study of the community, which is deeply needed. Moreover, future researchers could focus more on resilience as a consequence of external factors that affect the individual. The current literature hyperfocused on resilience as a natural trait, which can be misleading and detrimental, especially for those who are affected by their environment. Finally, future studies that focus on Latinx samples should examine discrimination and its multiple forms for Spanish-only speakers as well. Further research on specific types of discrimination as predictors for coping mechanisms such as resilience can further support clinicians serving marginalized populations. Finally, it is essential to remember that each individual BIPOC response is unique and cannot be fully generalized to entire communities. Therefore, the levels of resilience and the way resilience looks will vary depending on the individual, its membership to racially marginalized groups, and other external factors. And the need for studies that explore resilience among individuals with multiple marginalized identities is even bigger (Aguilera \& Barrita, 2021).

\section{Limitations}

Naturally, no study is exempt from limitation, and the final 9 articles selected are no exception. By analyzing previous studies whose sample partially represented the BIPOC community, it is essential to mention that while there are many articles discussing the African American, Latinx, and Asian American experience, there is a concerning lack of research around the Native American community. Moreover, even though the nine final studies went through rigorous exclusion criteria does not mean that the analysis of the results presented in this systematic review is generalizable to the entire population. The strength of the analysis can be affected by the subjective analysis of results, and the biased towards studies that presented the relationship between discrimination and resilience. Despite these limitations, this systematic review provides the connection to the development of better designed and BIPOC oriented research on the topic of resilience.

\section{Conclusion}

Resilience is a relevant concept that is attributed to those who persist in the face of difficulty. The timeliness of the concept derives from recent global struggles, such as the COVID-19 pandemic, but it also stems from the difficulties faced by minorities in a system of power dynamics that leads to these struggles and stressors from which they have to recover. From the studies selected in this review, one can imply external factors are essential to the development of effective coping strategies such as a resilient mentality and attitude, therefore the most appropriate definition found in this systematic review reveals that resilience is a complex process in which the individual and the environment interconnect to create a protective and positive result (Jackson et al., 2013). The importance of resilience as a theoretical framework should not be underestimated because it provides meaningful and helpful information about the concept and its relationship to other significant variables. Still, given that only a few studies used a reliable and valid method of operationalization, future research on resilience should seek to prioritize objective measurement procedures that are replicable in future studies.

\section{References}

Agnes, M. (Ed.). (2005). Webster's new college dictionary. Cleveland, $\mathrm{OH}$ : Wiley.

Aguilera, B., \& Barrita, A. (2021). Resilience in LGBTQ PoC. In J.J. Garcia (Ed.) Heart, Brain and Mental Health Disparities for LGBTQ People of Color (1st ed., pp. 137-145). Palgrave Macmillan (Springer Nature). https://doi.org/10.1007/978-3-030-70060-7_11

Austin, J. L., Jeffries, E. F., Winston, W., \& Brady, S. S. (2021). Race-related stressors and resources for resilience: Associations with emotional health, conduct problems, and academic investment among African American early adolescents. Journal of the American Academy of Child and Adolescent Psychiatry. https://doi.org/10.1016/j.jaac.2021.05.020

Barrita, A., \& Wong-Padoongpatt, G. (2021, in press). Resilience and Queer people. In K. Strunk \& S.A. Shelton (Eds.), Encyclopedia of Queer Studies in Education. Brill.

Bakić, Helena. (n.d.). Resilience and disaster research: Definitions, measurement, and future directions. Psihologijske Teme, 28(3), 529547. 
Bourbeau, P. (2018). A Genealogy of Resilience. International Political Sociology, 12(1), 1935. https://doi.org/10.1093/ips/olx026

Brown, D. L., \& Tylka, T. L. (2011). Racial discrimination and resilience in African American young adults: Examining racial socialization as a moderator. Journal of Black Psychology, 37(3), 259-285. https://doi.org/10.1177/0095798410390689

Burt, C. H., Simons, R. L., \& Gibbons, F. X. (2012). Racial discrimination, ethnic-racial socialization, and crime: A micro-sociological model of risk and resilience. American Sociological Review, 77(4), 648-677. https://doi.org/10.1177/0003122412448648

Burt, C. H., Lei, M. K., \& Simons, R. L. (2017). Racial discrimination, racial socialization, and crime. Social Problems, 64(3), 414-438. https://doi.org/10.1093/socpro/spw036

Campbell-Sills, L., \& Stein, M. B. (2007).

Psychometric analysis and refinement of the Connor-Davidson resilience scale (CD-RISC): Validation of a 10-item measure of resilience. Journal of Traumatic Stress, 20(6), 10191028. https://doi.org/10.1002/jts.20271

Carranza, M. E. (2007). Building resilience and resistance against racism and discrimination among Salvadorian female youth in Canada. Child \& Family Social Work, 12(4), 390-398. https://doi.org/10.1111/j.13652206.2007.00492.x

Carter, D. A. (2012). Black achievers' experiences with racial spotlighting and ignoring in a predominantly white high school. Teachers College Record (1970), 114(10).

Connor, K.M. \& Davidson, J. R. . (2003).

Development of a new resilience scale: The Connor-Davidson Resilience Scale (CDRISC). Depression and Anxiety, 4(2), 76-82. https://doi.org/10.1002/da.10113

Curtis, W. J., \& Cicchetti, D. (2003). Moving research on resilience into the 21 st century: Theoretical and methodological considerations in examining the biological contributors to resilience. Development and Psychopathology, 15(3), 773-810. https://doi.org/10.1017/S0954579403000373
Guarnizo Guzmán, C.P., García Martín, M.B., Suárez Falcón, J.C. \& Sierra, M.A. (2019).

Psychometric Properties of the ConnorDavidson Resilience Scale (CD-RISC) on Vulnerable Colombian Adolescents. Revista Internacional de Psicología y Terapia Psicológica, 19(3), 277-289.

Guyll, M., Madon, S., Prieto, L., \& Scherr, K. C. (2010). The potential roles of self-fulfilling prophecies, stigma consciousness, and stereotype threat in linking Latino/a ethnicity and educational outcomes. Journal of Social Issues, 66(1), 113-130. https://doi.org/10.1111/j.15404560.2009.01636.x

Heritage, B., Al Asadi, A. A., \& Hegney, D. G. (2021). Examination of the Connor-Davidson resilience scale 10 (CD-RISC-10) using the polytomous Rasch model. Psychological Assessment, 33(7), 672-684. https://doi.org/10.1037/pas0001011

Hu, T., Zhang, D., \& Wang, J. (2015). A metaanalysis of the trait resilience and mental health. Personality and Individual Differences, $76,18-27$. https://doi.org/10.1016/j.paid.2014.11.039

Jackson, K. F., Wolven, T., \& Aguilera, K. (2013). Mixed resilience: A study of multiethnic Mexican American stress and coping in Arizona. Family Relations, 62(1), 212-225. https://doi.org/10.1111/j.1741-

3729.2012.00755.x

Karaman, Mehmet A, Cavazos Vela, Javier, Aguilar, Alma A, Saldana, Karla, \& Montenegro, Maria C. (2019). Psychometric properties of U.S.-Spanish versions of the grit and resilience scales with a Latinx population. International Journal for the Advancement of Counselling, 41(1), 125-136. https://doi.org/10.1007/s10447-018-9350-2

Karairmak, O. (2009). Establishing the psychometric qualities of the Connor-Davidson Resilience Scale (CD-RISC) using exploratory and confirmatory factor analysis in a trauma survivor sample. Psychiatry Research, 179(3), 350-356. https://doi.org/10.1016/j.psychres.2009.09.012 
Kodama, C. M., \& Dugan, J. P. (2020). Understanding the role of collective racial esteem and resilience in the development of Asian American leadership self-efficacy. Journal of Diversity in Higher Education, 13(4), 355-367. https://doi.org/10.1037/dhe0000137

Kubiliene, N., Yan, M. C., Kumsa, M. K., \& Burman, K. (2015). The response of youth to racial discrimination: implications for resilience theory. Journal of Youth Studies, 18(3), 338356. https://doi.org/10.1080/13676261.2014.96353 5

Lee, J., Hong, J., Zhou, Y., \& Robles, G. (2020). The Relationships between loneliness, social support, and resilience among Latinx immigrants in the United States. Clinical Social Work Journal, 48(1), 99-109. https://doi.org/10.1007/s10615-019-00728-w

Liu, Y., Wang, Z., Zhou, C., \& Li, T. (2014). Affect and self-esteem as mediators between trait resilience and psychological adjustment. Personality and Individual Differences, 66, 92-97. https://doi.org/10.1016/j.paid.2014.03.023

Luthar, S. S., Cicchetti, D., \& Becker, B. (2000). The construct of resilience: A critical evaluation and guidelines for future work. Child Development, 71(3), 543-562. https://doi.org/10.1111/1467-8624.00164

Marsiglia, F., Booth, J. M., Baldwin, A., \& Ayers, S. (2013). Acculturation and Life Satisfaction Among Immigrant Mexican Adults. Advances in Social Work, 14(1), 49-64. https://doi.org/10.18060/3758

PeConga, E.K., Gauthier, G. M., Holloway, A., Walker, R. S. W., Rosencrans, P. L., Zoellner, L. A., \& Bedard-Gilligan, M. (2020).

Resilience Is Spreading: Mental Health Within the COVID-19 Pandemic. Psychological Trauma, 12(S1), S47-S48. https://doi.org/10.1037/tra0000874

PRISMA. (2021). http://prisma-statement.org/.

Romero, A. J., Edwards, L. M., Fryberg, S. A., \& Orduña, M. (2014). Resilience to discrimination stress across ethnic identity stages of development. Journal of Applied
Social Psychology, 44(1), 1-11.

https://doi.org/10.1111/jasp.12192

Sanchez, D., Adams, W. N., Arango, S. C., \& Flannigan, A. E. (2018). Racial-ethnic microaggressions, coping strategies, and mental health in Asian American and Latinx American college students: A mediation model. Journal of Counseling Psychology, 65(2), 214-225. https://doi.org/10.1037/cou0000249

Silver, L. (2021, March 18). More people globally see racial, ethnic discrimination as a serious problem in the U.S. than in their own society. Pew Research Center. Retrieved February 24, 2022, from https://www.pewresearch.org/facttank/2021/11/02/more-people-globally-seeracial-ethnic-discrimination-as-a-seriousproblem-in-the-u-s-than-in-their-own-society/

Smith, B., Dalen, W., Wiggins, J., Tooley, K., Christopher, E., \& Bernard, P. (2008). The Brief Resilience Scale: Assessing the ability to bounce back. International Journal of Behavioral Medicine, 15(3), 194-200. https://doi.org/10.1080/10705500802222972

Spence, N. D., Wells, S., Graham, K., \& George, J. (2016). Racial discrimination, cultural resilience, and stress. The Canadian Journal of Psychiatry, 61(5), 298-307. https://doi.org/10.1177/0706743716638653

Sue, D. W., Lin, A. I., Torino, G. C., Capodilupo, C. M., \& Rivera, D. P. (2009). Racial microaggressions and difficult dialogues on race in the classroom. Cultural Diversity and Ethnic Minority Psychology, 15, 183-190. https://doi:10.1037/a0014191

Umaña-Taylor, A. J., Tynes, B. M., Toomey, R. B., Williams, D. R., \& Mitchell, K. J. (2015). Latino adolescents' perceived discrimination in online and offline Settings: An examination of cultural risk and protective factors.

Developmental Psychology, 51(1), 87-100. https://doi.org/10.1037/a0038432

Ungar, M.H. (2013). Resilience, Trauma, Context, and Culture. Trauma, Violence \& Abuse, 14(3), 255-266. https://doi.org/10.1177/1524838013487805

Wittrup, A. R., Hussain, S. B., Albright, J. N., Hurd, N. M., Varner, F. A., \& Mattis, J. S. (2019). 
Natural mentors, racial pride, and academic engagement among Black adolescents. Youth \& Society, 51(4), 463-483.

https://doi.org/10.1177/0044118X16680546

Wong, G., Derthick, A. O., David, E. J. R., Saw, A., \& Okazaki, S. (2014). The what, the why, and the how: A review of racial microaggressions research in psychology. Race and Social Problems, 6(2), 181-200. https://doi.org/10.1007/s12552-013-9107-9

Wong-Padoongpatt, G., \& Barrita, A. (2021, in press). Racial microaggressions and selfesteem. In J. L. Chin, Y. E. Garcia \& A. Blume (Eds.) The Psychology of Inequity: Motivation and Beliefs (Vol. 1, 1st ed.). Praeger 
Appendix A: Table 1. Phase 1 search criteria

\begin{tabular}{|c|c|c|c|c|c|c|c|c|c|}
\hline Resource & $\begin{array}{l}\text { Date search } \\
\text { conducted }\end{array}$ & $\begin{array}{c}\text { Search } \\
\text { type/terms }\end{array}$ & $\begin{array}{c}\text { Years } \\
\text { covered by } \\
\text { search }\end{array}$ & Limits & Results & $\begin{array}{l}\text { Search result } \\
\text { refinements }\end{array}$ & $\begin{array}{l}\text { Refined } \\
\text { results }\end{array}$ & Notes & $\begin{array}{c}\text { Papers } \\
\text { used }\end{array}$ \\
\hline EBSCO - all & $6 / 15 / 2021$ & $\begin{array}{l}\text { Advanced } \\
\text { Resilience AND } \\
\text { dicrimination }\end{array}$ & 2010 to present & $\begin{array}{l}\text { Scholarly (Peer } \\
\text { Reviewed) } \\
\text { Journals }\end{array}$ & 2,745 & $\begin{array}{l}\text { Looking at titles } \\
\text { with the word } \\
\text { "resilience" on it. } \\
\text { (TI TITLE) } \\
\text { And full text }\end{array}$ & $\begin{array}{l}338 \rightarrow 101 \text { (after } \\
\text { eliminating } \\
\text { duplicates) }\end{array}$ & $\begin{array}{l}\text { Looking at titles } \\
\text { only }\end{array}$ & 9 relevant titles \\
\hline $\begin{array}{l}\text { APA } \\
\text { PSycarticles } \\
\text { Full-text }\end{array}$ & $6 / 15 / 2021$ & $\begin{array}{l}\text { Advanced } \\
\text { search - } \\
\text { resilience AND } \\
\text { discrimination }\end{array}$ & $\begin{array}{l}2010 \text { to the } \\
\text { present }\end{array}$ & $\begin{array}{l}\text { Scholarly (Peer } \\
\text { Reviewed) } \\
\text { Journals }\end{array}$ & 79 & & 79 & $\begin{array}{l}\text { Looking at titles } \\
\text { only }\end{array}$ & 1 Relevant titles \\
\hline $\begin{array}{l}\text { Sociological } \\
\text { Abstracts }\end{array}$ & $6 / 15 / 2021$ & $\begin{array}{l}\text { Advanced } \\
\text { search - } \\
\text { resilience AND } \\
\text { discrimination }\end{array}$ & $\begin{array}{l}2010 \text { to the } \\
\text { present }\end{array}$ & Peer reviewed & 20 & & 20 & $\begin{array}{l}\text { Looking at titles } \\
\text { only }\end{array}$ & 2 Relevant titles \\
\hline EBSCO - all & $6 / 16 / 2021$ & $\begin{array}{l}\text { Advanced } \\
\text { search - } \\
\text { resilience (only) }\end{array}$ & $\begin{array}{l}2010 \text { to the } \\
\text { present }\end{array}$ & Peer reviewed & 145,297 & $\begin{array}{l}\text { Looking at titles } \\
\text { with the word } \\
\text { "resilience" on it. } \\
\text { (TI TITLE) } \\
\text { And full-text, } \\
\text { subject = } \\
\text { Psychology }\end{array}$ & $\begin{array}{l}434 \rightarrow 223 \text { (after } \\
\text { eliminating } \\
\text { duplicates) }\end{array}$ & $\begin{array}{l}\text { Looking at titles } \\
\text { only }\end{array}$ & 5 Relevant titles \\
\hline $\begin{array}{l}\text { APA Psycinfo - } \\
\text { full-text }\end{array}$ & $6 / 16 / 2021$ & $\begin{array}{l}\text { Advanced } \\
\text { search - } \\
\text { resilience }\end{array}$ & $\begin{array}{l}2010 \text { to the } \\
\text { present }\end{array}$ & Peer reviewed & 18,485 & full text & 6,147 & $\begin{array}{l}\text { Looking at titles } \\
\text { only }\end{array}$ & 9 Relevant titles \\
\hline $\begin{array}{l}\text { Sociological } \\
\text { abstracts }\end{array}$ & $6 / 16 / 2021$ & $\begin{array}{l}\text { Advanced } \\
\text { search - } \\
\text { resilience }\end{array}$ & $\begin{array}{l}2010 \text { to the } \\
\text { present }\end{array}$ & Peer reviewed & 11,361 & $\begin{array}{l}\text { subject=resilienc } \\
\mathrm{e},\end{array}$ & 2,901 & $\begin{array}{l}\text { Looking at titles } \\
\text { only }\end{array}$ & 5 Relevant titles \\
\hline
\end{tabular}

